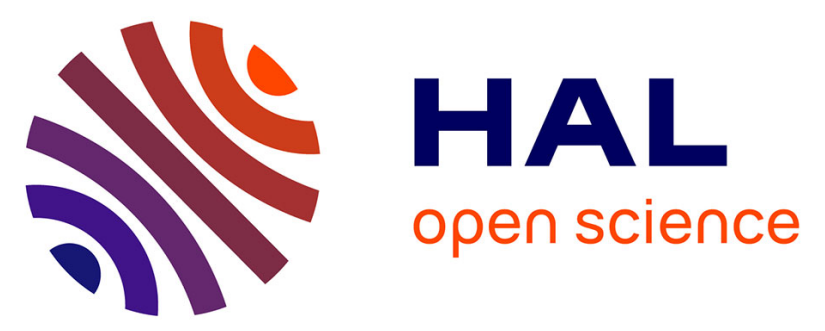

\title{
A methodology based on reduced schemes to compute autoignition and propagation in internal combustion engines
}

Antony Misdariis, Olivier Vermorel, Thierry Poinsot

\section{- To cite this version:}

Antony Misdariis, Olivier Vermorel, Thierry Poinsot. A methodology based on reduced schemes to compute autoignition and propagation in internal combustion engines. Proceedings of the Combustion Institute, 2015, vol. 35 ( $\mathrm{n}^{\circ} 3$ ), pp. 3001-3008. 10.1016/j.proci.2014.06.053 . hal-01117063

\author{
HAL Id: hal-01117063 \\ https://hal.science/hal-01117063
}

Submitted on 16 Feb 2015

HAL is a multi-disciplinary open access archive for the deposit and dissemination of scientific research documents, whether they are published or not. The documents may come from teaching and research institutions in France or abroad, or from public or private research centers.
L'archive ouverte pluridisciplinaire HAL, est destinée au dépôt et à la diffusion de documents scientifiques de niveau recherche, publiés ou non, émanant des établissements d'enseignement et de recherche français ou étrangers, des laboratoires publics ou privés. 


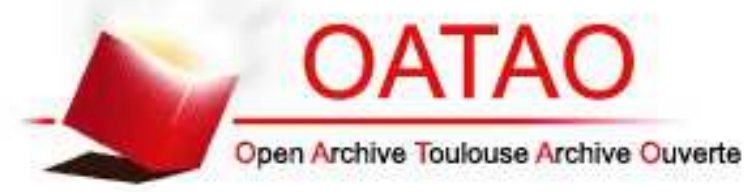

\section{Open Archive TOULOUSE Archive Ouverte (OATAO)}

OATAO is an open access repository that collects the work of Toulouse researchers and makes it freely available over the web where possible.

This is an author-deposited version published in : http://oatao.univ-toulouse.fr/ Eprints ID : 13524

To link to this article : DOI :10.1016/j.proci.2014.06.053

URL : http://dx.doi.org/10.1016/j.proci.2014.06.053

To cite this version : Misdariis, Antony and Vermorel, Olivier and Poinsot, Thierry A methodology based on reduced schemes to compute autoignition and propagation in internal combustion engines. (2015) Proceedings of the Combustion Institute, vol. 35 ( $\left.{ }^{\circ} 3\right)$. pp. 3001-3008. ISSN 1540-7489

Any correspondance concerning this service should be sent to the repository administrator: staff-oatao@listes-diff.inp-toulouse.fr 


\title{
A methodology based on reduced schemes to compute autoignition and propagation in internal combustion engines
}

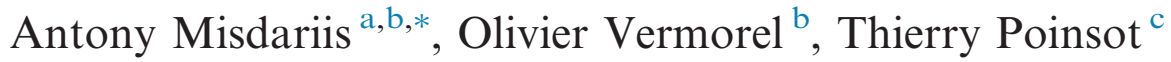 \\ ${ }^{a}$ Renault SAS, 1 Allée Cornuel, 91570 Lardy, France \\ ${ }^{\mathrm{b}}$ CERFACS, CFD Team, 42 Avenue G. Coriolis, 31057 Toulouse Cedex 01, France \\ ${ }^{\mathrm{c}}$ Institut de Mécanique des Fluides de Toulouse, CNRS, Avenue C. Soula, 31400 Toulouse, France
}

\begin{abstract}
The prediction of autoignition (AI) delay is an essential prerequisite to account for abnormal combustions (e.g. knock or super knock) that can appear in Internal Combustion (IC) engines. In this paper, a simple model called Ignition to Propagation Reduced Scheme (IPRS) is proposed to add AI predictions in reduced chemical schemes, which are classically used to compute in-cylinder combustion in the context of Large Eddy Simulations (LES). The IPRS principle is to use a single two-reaction reduced scheme and adapt the pre-exponential factor of the fuel oxidation reaction as a function of the temperature: one value is used at low temperatures to correctly predict AI delays and an other one can be used at higher temperatures, where heat release occurs, to keep the flame propagation properties of the chemical scheme. After a first section that introduces the model, Perfectly Stirred Reactors and 1D flames simulations are used to verify that: (1) the modification of the pre-exponential constant of the Arrhenius law at low temperature does not alter the propagation properties of the reduced scheme and (2) this modification is sufficient to accurately predict AI delays. The IPRS model captures autoignition times exactly like a full chemical scheme in a compressed zero dimensional test case representative of engine compression. In the last section this model is applied to 1D single hot spot simulations to investigate the modes of reaction after autoignition.
\end{abstract}

Keywords: LES; Knock; Autoignition; Internal combustion engine; Reduced scheme

\section{Introduction}

During the last decade engine downsizing has revealed to be a useful path to improve the efficiency of Internal Combustion (IC) engines.

\footnotetext{
* Corresponding author at: CERFACS, CFD Team, 42 Avenue G. Coriolis, 31057 Toulouse Cedex 01, France. Fax: +330561193000.

E-mail address: misdariis@cerfacs.fr (A. Misdariis).
}

This technique allows to operate engines in a zone of higher efficiency by reducing the cylinders size and by increasing the pressure inside the chamber thanks to turbo chargers. It is commonly used in the industry up to a downsizing level of about $25 \%$. Beyond this level abnormal combustions such as knock or super knock start occurring due to the high pressure and temperature conditions inside the cylinder. Understanding abnormal combustions is a main field of research inside the IC engine 
community in order to reach higher levels of downsizing. Previous studies [1-3] proved that LES is a powerful tool able to reproduce unsteady phenomena occurring in piston engines. However, to study abnormal combustion in IC engines, a model able to accurately predict Auto-Ignition (AI) delays has to be added to the LES solver. Because of the complexity of low temperature kinetics [4-7], most modeling approaches rely on tabulation of ignition delays obtained from zero dimensional ignition computations [8] or from representative 1D flamelets [9]. Some reduced schemes compatible with LES (limited to a few reactions and species) for the primary reference fuels are also available $[10,11]$ but they are limited to the AI delay prediction and have to be associated to other models for high temperature reactions. Here an alternative solution is explored: a single two-step reduced scheme is used to describe both AI and propagation. It is called IPRS (Ignition to Propagation Reduced Scheme). The scope is not to reproduce the complex path of chemical reactions leading to AI but only to tune the reduced scheme reactions such that the AI delay is the same as the one obtained with complex chemistries. The model is introduced in the next section and validated on AI cases and 1D premixed flames. Homogeneous zero dimensional flow elements representative of IC engine are then simulated where complex chemistries AI delays are available to assess the accuracy of the IPRS model. In the last section the model is applied to non-homogeneous cases where autoignition phenomena can lead to detonation. The paper focuses on two fuels (pure isooctane and a gasoline surrogate called Sur95t in Pera et al. [12]) but the methodology can be extended to other fuels.

\section{Predicting autoignition delay with a two-step chemistry}

In reactive LES the source terms $\dot{\omega}_{T}$ and $\dot{\omega}_{k}$ in the energy and the species conservation equations have to be closed. For a mechanism including $M$ reactions between $N$ reactants and with $W_{k}$ the molar weight of species $k$ :

$\dot{\omega}_{k}=\sum_{j=1}^{M} \dot{\omega}_{k j}=W_{k} \sum_{j=1}^{M} v_{k j} Q_{j}$

where $v_{k j}=v_{k j}^{\prime \prime}-v_{k j}^{\prime}$ is the global stoichiometric coefficient of species $k$ in reaction $j$. The progress rate $Q_{j}$ is defined by:

$Q_{j}=K_{f, j} \prod_{k=1}^{N}\left(\frac{\rho Y_{k}}{W_{k j}}\right)^{v_{k j}^{\prime}}-K_{r, j} \prod_{k=1}^{N}\left(\frac{\rho Y_{k}}{W_{k}}\right)^{v_{k j}^{\prime \prime}}$

In this relation $\rho$ is the density, $Y_{k}$ represents the species mass fractions and $K_{f, j}\left(\right.$ respectively $K_{r, j}$ ) is the forward (respectively reverse) rate of reaction $j$ obtained with the Arrhenius law:
$K_{f, j}=T^{\beta_{j}} A_{f, j} \exp \left(-\frac{E_{a, j}}{\mathcal{R} T}\right)$

with $R$ the perfect gas constant, $T$ the temperature, $A_{f, i}$ the pre-exponential constant, $E_{a, j}$ the activation energy and $\beta_{j}$ the temperature exponent. For propagating flames the most important parameters that have to be accurately predicted by the source term closure are the laminar flame speed $S_{L}^{0}$, the flame thickness $\delta_{L}^{0}$ and the adiabatic flame temperature $T_{a d}$. Single-step chemical schemes can provide an accurate description of flame propagation process but they can not predict the burned gas temperature over a wide range of equivalence ratios because it depends on the species enthalpies. A simple solution to this problem has been used in the gas turbine community $[13,14]$ by adding a reversible reaction between $\mathrm{CO}$ and $\mathrm{CO}_{2}$. This is sufficient to capture both flame speed and adiabatic temperature over all relevant compositions. The resulting two-step schemes family can be written:

$$
\begin{aligned}
C_{x} H_{2 x+2}+ & \left(x+\frac{x+1}{2}\right)\left(\mathrm{O}_{2}+a \mathrm{~N}_{2}\right) \rightarrow \quad x \mathrm{CO}_{2} \\
& +(x+1) \mathrm{H}_{2} \mathrm{O}+\left(x+\frac{x+1}{2}\right) a \mathrm{~N}_{2}
\end{aligned}
$$

$\mathrm{CO}+\frac{1}{2} \mathrm{O}_{2} \rightarrow \mathrm{CO}_{2}$

Table 1 summarizes the Arrhenius coefficients of the two-step mechanism classically used to compute isooctane/air flames propagation. The reaction exponents differ from the stoichiometric coefficients and are adjusted to obtain the right dependence of the flame speed in pressure. This scheme was designed to reproduce the Hasse et al. experiments [15]. Reduced schemes are widely used and several authors point out their accuracy in a wide range of configurations $[2,16]$. However they obviously fail to capture AI delays which are driven by low temperature chain reactions and the chemistry of radicals such as alkylperoxy or hydroperoxyalkyl [4-7]. All studies show a correlation between the AI delay $\tau_{A I}$ and the pre-exponential of the Arrhenius law:

$\tau_{A I} \sim \frac{1}{A_{f, j}} \exp \left(\frac{E_{a, j}}{\mathcal{R} T}\right)$

Table 1

Arrhenius parameters for the $\mathrm{C}_{8} \mathrm{H}_{18}$ /air scheme.

\begin{tabular}{lllll}
\hline & $\begin{array}{l}\mathrm{C}_{8} \mathrm{H}_{18} \\
\text { oxidation }\end{array}$ & \multicolumn{2}{l}{$\begin{array}{l}\mathrm{CO}-\mathrm{CO}_{2} \\
\text { equilibrium }\end{array}$} \\
\hline$E_{a}[\mathrm{cal} / \mathrm{mol}]$ & $3.6 \cdot 10^{4}$ & & $1.4 \cdot 10^{5}$ & \\
$\mathrm{~A}\left[\mathrm{~cm}^{3} / \mathrm{mol}\right]$ & $5.443 \cdot 10^{12}$ & & $2.0 \cdot 10^{5}$ & \\
$\beta_{j}[-]$ & 0.1 & & 0.0 & \\
Reaction & $n_{\mathrm{C}_{8} \mathrm{H}_{18}}$ & 1.1 & $n_{\mathrm{CO}}$ & 1.00 \\
exponents [-] & $n_{\mathrm{O}_{2}}$ & 0.54 & $n_{\mathrm{O}_{2}}$ & 0.50 \\
\hline
\end{tabular}


Equation (6) suggests that a simple adjustment of the pre-exponential constant $A_{f, j}$ may give correct predictions of AI delays, even for basic chemical schemes. Of course, the values of the pre-exponential constant $A_{\text {prop }}$ that ensure the right laminar flame speed $S_{L}^{0}$ and the values $A_{A I}$ that will provide the right AI delay are different but the two modes of combustion previously described (i.e. propagation and $\mathrm{AI}$ ) are driven by processes occurring in two different ranges of temperature: $\mathrm{AI}$ is initiated at low temperatures while the flame propagation is mainly driven by high temperature mechanisms. In order to predict both propagation and AI with a reduced mechanism, the idea of IPRS is to take advantage of this decoupling in temperature and make the pre-exponential constant vary with temperature (Fig. 1):

$A_{f, j}=A_{A I}+\left(A_{\text {prop }}-A_{A I}\right)\left[\frac{1+\tanh \left(\frac{T-T_{c}}{\sigma}\right)}{2}\right]$

$T_{c}$ is the cross-over temperature where $A_{f, j}$ goes from $A_{A I}$ to $A_{\text {prop }} . \sigma$ is a parameter introduced to adjust the steepness of the constant change with temperature. The idea of making chemical constants change with the local conditions is not new [17-19] but it is introduced here to capture both $\mathrm{AI}$ and propagation in an IC engine. Of course, such a reduced scheme will not reproduce all details of an actual AI process and in particular the cold flame phenomena but the AI delay will match the one computed with complex chemistry as shown in Fig. 2. Note that methods based on tabulation of AI times are also limited to the objective of correctly capturing the AI delays and nothing more. One advantage of IPRS is that the same chemical scheme can be used during the whole combustion process, avoiding to couple two models as often done with tabulation techniques: one before AI (using tabulated times) and another one after ignition.

The methodology followed to determine $A_{A I}$ is to first characterize each fuel in terms of AI times over the range of pressure and temperature of interest using complex chemistries and a set of Perfectly Stirred Reactors (PSR) computations

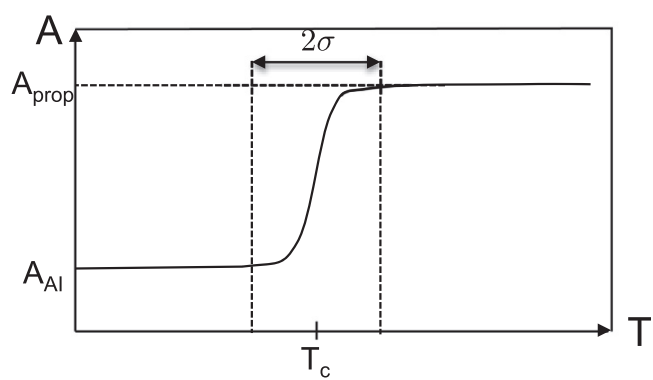

Fig. 1. Schematic of the evolution of the pre-exponential constant across the flame front with the IPRS model.

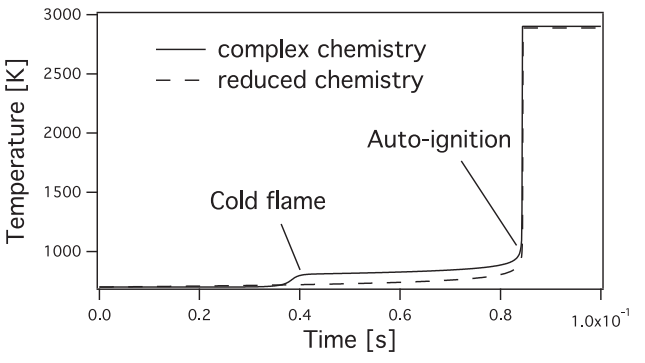

Fig. 2. Temperature evolution in a stoichiometric Perfectly Stirred Reactor with a complex chemistry and IPRS for isooctane at $T_{1}=700 \mathrm{~K}$ and $P_{1}=11$ bar.

with a $0 D$ chemistry software. In the present study Cantera was used [20]. The complex schemes used as reference are presented in Table 2. The reference AI delays for isooctane and for the gasoline surrogate are shown in Fig. 3. A series of AI delays is then computed with the two-step mechanism under the same conditions of pressure and temperature to find the values of the pre-exponential constant $A_{A I}$ that will predict the same AI time as the complex chemical scheme. Finally, the $A_{A I}$ values of the pre-exponential constant are tabulated as a function of temperature and pressure of the fresh gas to be used in the 3D LES solver. For isooctane, the table used for the pre-exponential constant of the fuel oxidation reaction (Eq. (4)) to predict AI delays is presented in Fig. 4 while the standard constant from Table 1 is used for the propagation. The tabulation is only performed here versus pressure and temperature because, in the target application, the charge is perfectly premixed but the method can easily include the effect of other parameters such as dilution or equivalence ratio.

An other difficulty arises when applying this model to a configuration with variable volume such as IC engines: the initial pressure and temperature can not be used to read the $A_{A I}$ table because the AI delay is affected by compression and expansion. Using local and instantaneous conditions is not a solution either because the very small heat release that occurs even before AI may change the local temperature. This may be particularly critical if the temperature falls within the Negative Temperature Coefficient (NTC) zone, where small variations of temperature can lead to very different $A_{A I}$. To obtain the right value

Table 2

Complex chemistry mechanisms used as reference for the IPRS method.

\begin{tabular}{lll}
\hline & N species & N reactions \\
\hline Jerzembeck [21] & 104 & 403 \\
Anderlhor [22] & 538 & 3000 \\
\hline
\end{tabular}



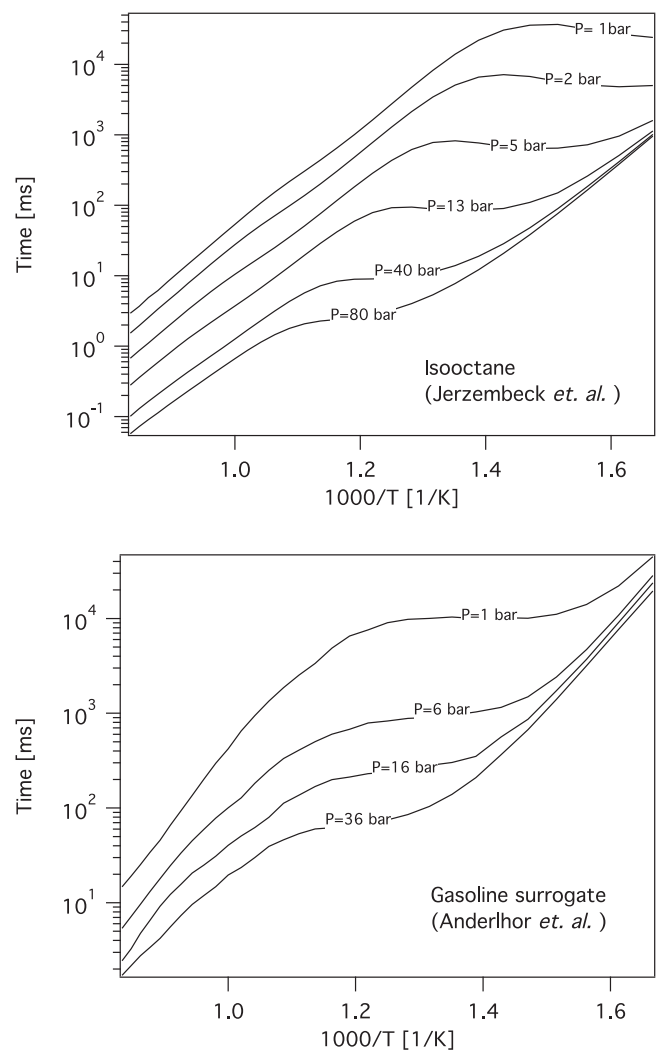

Fig. 3. AI times of isooctane (top) and gasoline surrogate (bottom) in PSR with complex chemistries.

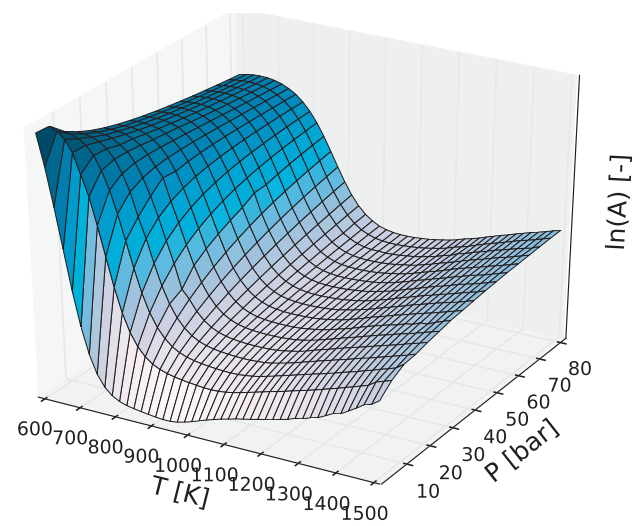

Fig. 4. Pre-exponential constant $A_{A I}$ table used in the 3D LES solver and designed to reproduce the AI delays of isooctane.

for $A_{A I}$, an estimation of the fresh gas temperature must be used. Here a method similar to the one used in the TKI model [8] is implemented. It consists in the transport of the fresh gas enthalpy with sources terms accounting for heat transfers.

\section{Test cases and validation}

The IPRS approach is first tested by computing (1) laminar premixed flame speeds (Section 3.1) and (2) AI times (Section 3.2). For both cases, the IPRS two-step scheme is compared to the complex schemes of $[21,22]$ for isooctane or gasoline/ air flames. All computations are performed with Cantera.

\subsection{Laminar premixed flame speed}

To evaluate the capacity of the IPRS scheme to correctly predict laminar flame speeds and determine the proper value of the cross-over temperature $T_{c}$ used to change the pre-exponential constant, a series of stoichiometric premixed laminar isooctane/air flames was computed for a fresh gas temperature $T_{1}$ of $800 \mathrm{~K}$ and pressures $P_{1}$ varying from 1 bar to 40 bar. Figure 5 shows the laminar flame speed obtained with the IPRS scheme, normalized by its exact value (obtained with the complex scheme) as a function of the normalized cross-over temperature $\theta_{c}=\left(T_{c}-T_{1}\right) /\left(T_{2}-T_{1}\right)$, with $T_{2}$ the burned gas temperature. As soon as $\theta_{c}$ is less than 0.2 , the IPRS flame speed matches its exact (complex scheme) value, showing that the pre-exponential constant can, indeed, be modified at low temperature without affecting the flame speed. Another way to verify that $\theta_{c}=0.2$ is the cross-over temperature limit to correctly predict the flame propagation is to plot the reduced reaction rate $\dot{\omega}_{r}$ as a function of the reduced temperature $\theta$ in Fig. 6 for a 1D premixed flame. On the same graph, the pre-exponential constant $A_{f, j}$ is plotted as a function of the reduced temperature for the same 1D flame with the IPRS model and $\theta_{c}=0.15$ : in conditions where $A_{f, j}$ is altered by the IPRS model, i.e. for $\theta<0.2$, the reaction rate is almost equal to zero. As described in [23], this zone corresponds to the pre-heating zone mainly driven by convection and heat diffusion where the Arrhenius constants play no role. When the heat release starts increasing, $A_{f, j}$ is back to $A_{\text {prop }}$ which provides the right propagation properties. $\theta_{c}=0.15$ is used for the rest of this work.

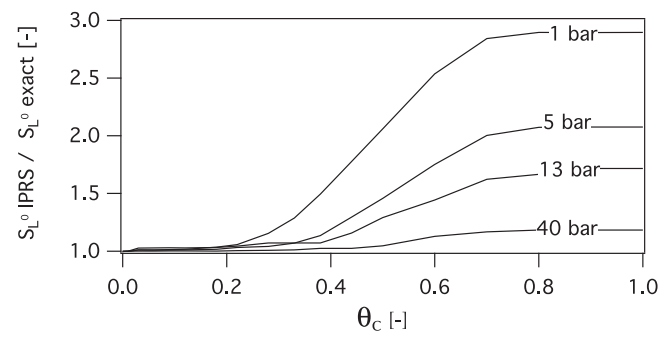

Fig. 5. Normalized laminar flame speed obtained with the IPRS model as a function of the reduced cross-over temperature $\theta_{c}=\left(T_{c}-T_{1}\right) /\left(T_{2}-T_{1}\right)$. Stoichiometric isooctane/air flames, $T_{1}=800 \mathrm{~K}$. 


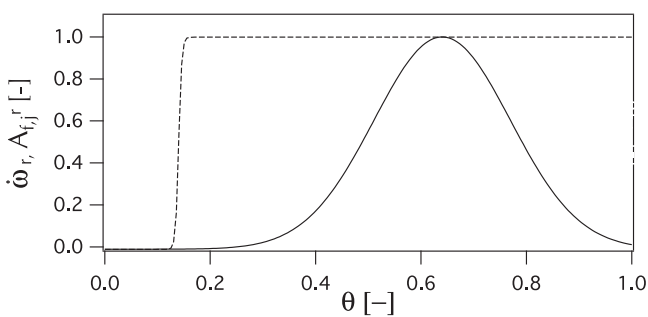

Fig. 6. Reduced reaction rate of the fuel oxydation reaction $\dot{\omega}_{r}=\dot{\omega} / \max (\dot{\omega})$ (solid line) and reduced preexponential constant $A_{f, j}^{r}=\left(A_{f, j}-A_{\text {prop }}\right) /\left(A_{A I}-A_{\text {prop }}\right)$ (dashed line) along a 1D stoichiometric isooctane/air laminar flame with $\theta_{c}=0.15$.

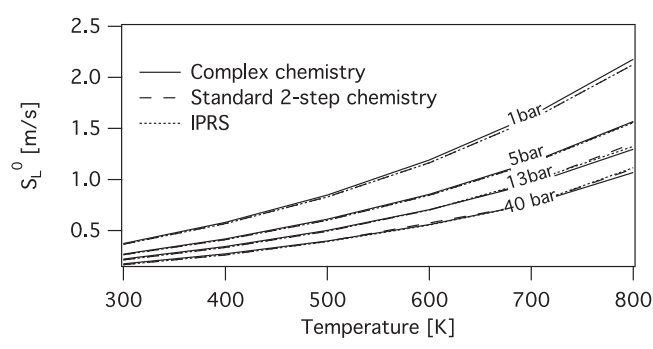

Fig. 7. Comparison of 1D stoichiometric isooctane/air laminar flame speed with complex chemistry, the standard two-step chemistry and the IPRS model.

Table 3

Geometrictal specifications of the compressed cylinder.

\begin{tabular}{lll}
\hline Bore & {$[\mathrm{mm}]$} & 86 \\
\hline Stroke & {$[\mathrm{mm}]$} & 82 \\
Connecting rod length & {$[\mathrm{mm}]$} & 137 \\
Compression ratio & {$[-]$} & 6.32 \\
Engine rotation speed & {$[\mathrm{rpm}]$} & 1200 \\
\hline
\end{tabular}

A new set of 1D flames is then computed to evaluate the model with $T_{1}$ varying from $300 \mathrm{~K}$ to $800 \mathrm{~K}$ and $P_{1}$ varying from 1 bar to 40 bar to check the behavior in IC engine like conditions. Results are compared to the same 1D flames computed without the AI model (i.e. with $A_{f, j}$ constant and equal to $A_{\text {prop }}$ ) and to Cantera computations performed with the complex schemes of Table 2. Figure 7 shows that the differences between the three computations are almost negligible over the whole range of temperature. These results thus validate the assumption that a modification of the pre-exponential constant at low temperatures does not affect the propagation behavior as long as the right constant $A_{\text {prop }}$ is used in the range of temperature where heat release occurs i.e. for $\theta>0.2$.

\subsection{Autoignition delays}

The AI delays predicted by the IPRS model are compared now to the complex schemes results. A first series of stoichiometric PSR are computed

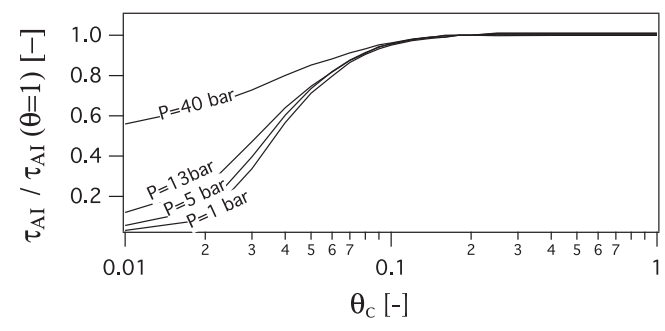

Fig. 8. Non-dimensional AI delay as a function of the reduced cross-over temperature $\theta_{c}=\left(T_{c}-T_{1}\right) /$ $\left(T_{2}-T_{1}\right)$.

with an initial temperature $T_{1}$ of $800 \mathrm{~K}$ and an initial pressure $P_{1}$ ranging from 1 to 40 bar. For each case the sensitivity of the AI delay to the crossover temperature $T_{c}$ is evaluated. Figure 8 shows that for all pressures, if $T_{c}$ is chosen such that $\theta_{c}>0.1$ the error on the AI delay is less than $5 \%$ and for $\theta_{c}=0.15$, less than $2 \%$. This confirms that the value $\theta_{c}=0.15$ chosen in Section 3.1 is a good trade off. This value is retained in the following to compute AI delays under a wide range of pressure and temperature. As shown in Fig. 9, for both fuels, the AI delays predicted by the IPSR model are very close to the ones predicted by the complex schemes of $[21,22]$. Even the NTC zone of isooctane (when $P<15$ bar) is correctly captured with this approach, demonstrating that a very simple chemical description can be efficient if (1) it is tuned on a complex chemistry scheme and (2) the objective is to capture AI delays only (no cold flame details). Note that, of course, the CPU cost of such an approach is extremely low compared to all other methods.

\section{Validation in a compressed zero dimensional autoigniting flow}

In order to evaluate the ability of the IPRS model to predict AI events in IC engines, a simplified configuration representing the compression of a flow element typical of a piston engine is computed. This test case corresponds to a zero dimensional evolution of a compressed flow where the initial composition corresponds to a premixed gasoline/air mixture. This mixture is compressed following a law which corresponds to the pressure change in a piston engine. The volume variation versus time is given by:

$$
\begin{aligned}
& v(\phi)=V_{0}+S[0.5 \mathrm{~s}(1-\cos \phi) \\
& \left.+l+\left(l^{2}-(0.5 \mathrm{~s})^{2} \sin ^{2} \phi\right)^{1 / 2}\right]
\end{aligned}
$$

where the equivalent Crank Angle (CA) is $\phi, V_{0}$ represents the initial volume, $s$ is the stroke and $l$ is the connecting rod length. The values used for these parameters are summarized in Table 3 . The mixture ignites after an autoignition time 

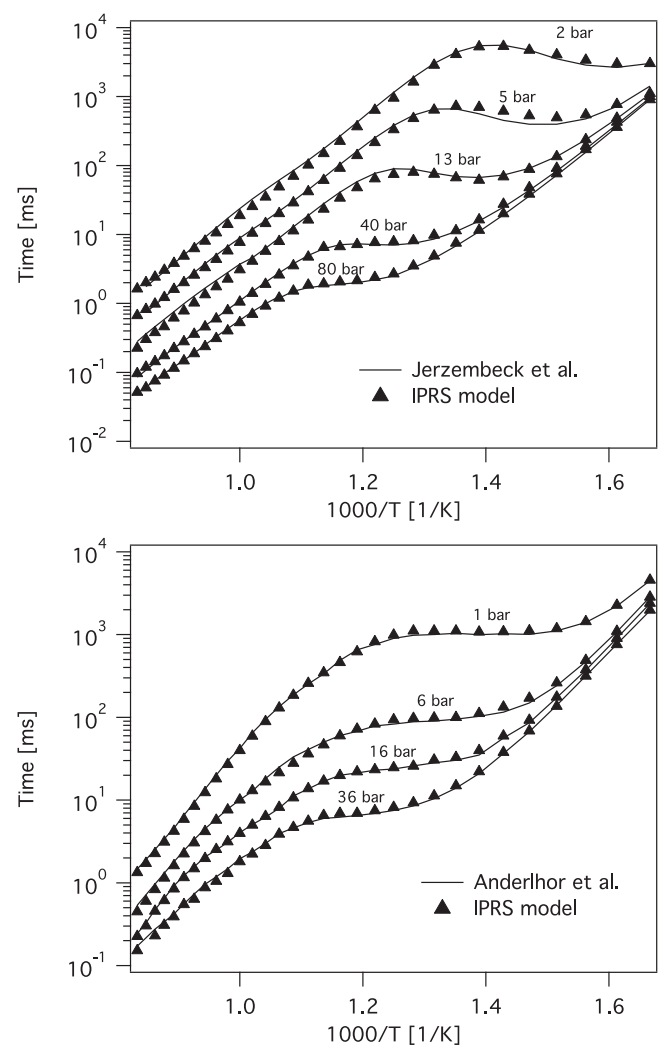

Fig. 9. Comparison of AI delays obtained with the IPSR model and the Cantera software for isooctane (top) and gasoline surrogate (bottom).

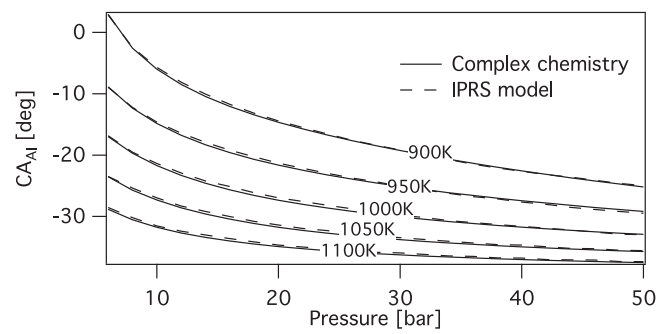

Fig. 10. AI delay in a stoichiometric gasoline/air compressed cylinder obtained with the IPRS model compared to the complex chemistry of [22] computed with Cantera.

$\tau_{A I}$ (or a crank angle $C A_{A I}$ ). The autoignition crank angle $C A_{A I}$ is plotted as a function of the initial pressure for different temperatures in Fig. 10. For the wide range of initial conditions evaluated here, the IPRS model gives exactly the same results as the complex chemistry validating the ability of the IPRS model to accurately predict AI delays in conditions favorable to abnormal combustions.

\section{Validation in a one dimensional flow: transition to detonation}

The previous section showed that IPRS can capture autoignition in homogeneous flows. When the flow is not homogeneous, autoignition can lead to complex flame structures and the IPRS model should be able to capture them. A representative test for such cases is autoignition in a onedimensional mixture, close to autoignition conditions, where the temperature is stratified $[24,25]$. Here we consider a hot spot zone of size $r_{0}$ where the temperature changes with an initial gradient $\frac{\partial T}{\partial x}$ (Fig. 11). In these situations, different modes of reaction can occur. The diagram proposed by Bradley and Kalghatgi [24] (Fig. 12) classifies theses modes depending on the dimensionless temperature gradient $\xi$ (Eq. (9)) and hot spot size $\epsilon$ (Eq. (10)).

$\xi=\left(\frac{\partial T}{\partial x}\right)\left(\frac{\partial T}{\partial x}\right)_{c}^{-1}$

$\epsilon=\frac{r_{0}}{a \tau_{e}}$

In these expressions $\left(\frac{\partial T}{\partial x}\right)_{c}=\frac{1}{a} \frac{\partial T}{\partial \tau_{A I}}$ is the critical gradient, $a$ is the speed of sound and $\tau_{e}$ the chemical excitation time defined as the time needed to go from $5 \%$ to $100 \%$ of the maximum heat release

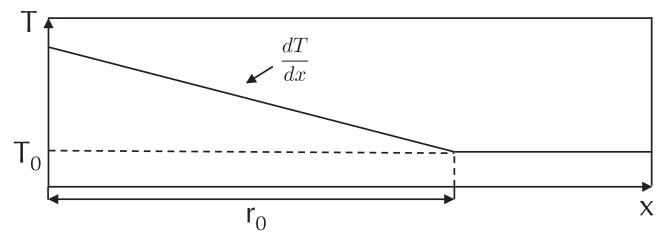

Fig. 11. Initial conditions for the non-homogeneous test case: one-dimensional hot spot.

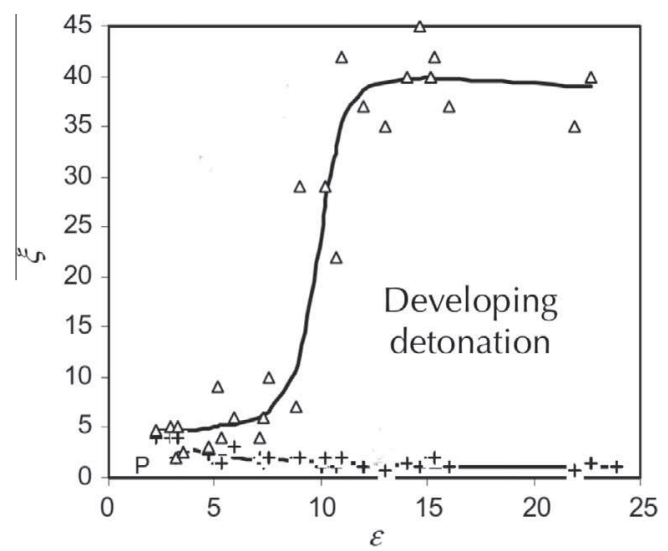

Fig. 12. Modes of reaction after hot spot autoignition as proposed by Bradley and Kalghatgi [24]. 
in a PSR [24]. One can identify four zones from this diagram: (i) if the temperature gradient is large compared to the autoignition delay gradient a subsonic autoignitive front will propagate inside the fresh gas; (ii) if this gradient is very small a thermal explosion will occur as this configuration tends towards PSR configurations. In other regions of the diagram the autoignition front can develop into a detonation wave (iv) or not (iii). To permit a transition to detonation the hot spot must be of a critical size ensuring that the residence time of the pressure wave generated by autoignition inside the hot spot is large enough compared to the chemical time feeding it (in practice several chemical times are needed). All these configurations were computed with the IPRS model: only configurations (iii) and (iv) are discussed here as (i) and (ii) are similar to the test cases shown in Sections 3.1 and 3.2.

The initial conditions consist of a 1D domain filled with a homogeneous stoichiometric isooctane/air mixture at 50 bar and a temperature of $1100 \mathrm{~K}$ outside of the hot spot. For (iii) the size of the hot spot is $4 \mathrm{~mm}$ with a linear gradient of $5 \mathrm{~K} / \mathrm{mm}$. This case corresponds to $\xi=16$ and $\epsilon=7$. A weak pressure wave is generated by the hot spot autoignition (Fig. 13) which is amplified up to 200 bar just before exiting the hot spot at $x=4 \mathrm{~mm}$ due to a coupling with the reaction front. At this point the autoignition/pressure wave speed reaches $1600 \mathrm{~m} / \mathrm{s}$ meaning that the transition to detonation is close. Outside the hot spot, the pressure wave and the autoignition wave velocities start diverging: the transition to detonation aborts and the peak pressure wave is reduced since it is not sustained by autoignition anymore. The same configuration is then simulated with a larger hot spot size of $10 \mathrm{~mm}$ with a temperature gradient
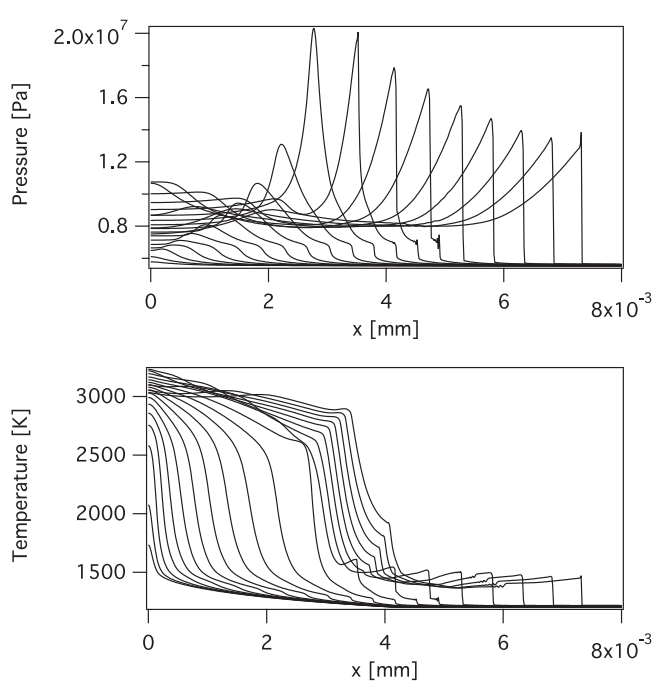

Fig. 13. Hot spot autoignition and failure to sustain a detonation outside the hot spot.
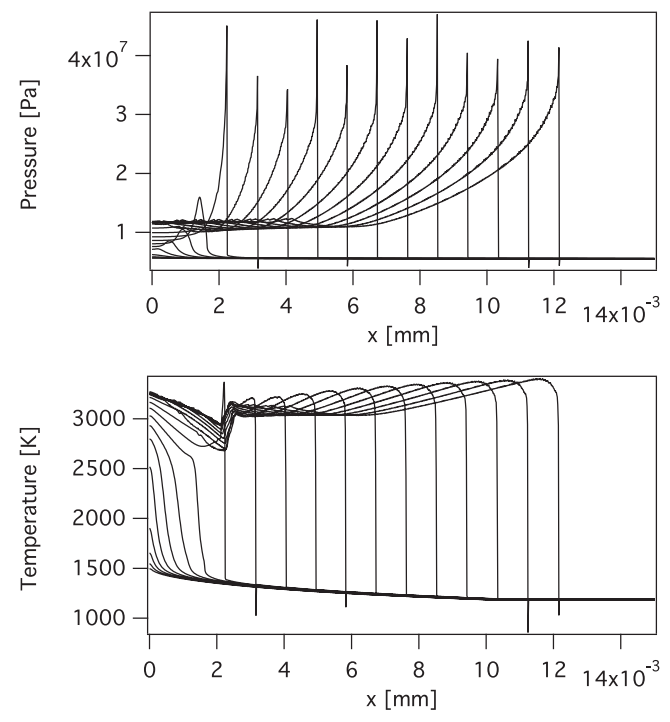

Fig. 14. Hot spot autoignition and transition to detonation outside the hot spot.

of $4 \mathrm{~K} / \mathrm{mm}$ which corresponds to $\xi=9$ and $\epsilon=25$. Figure 14 shows that after autoignition, the pressure wave and the reaction front couple inside the hot spot as in the previous configuration. However, the bigger hot spot radius enables a full coupling between the two waves which eventually propagate together at about $2000 \mathrm{~m} / \mathrm{s}$ : the pressure/autoignition waves remain coupled outside the hot spot and the strong pressure peak is not dissipated. This simple configuration illustrates the accuracy of the IPRS model: in addition to the prediction of autoignition delays it is able to accurately predict the different modes of propagation after autoignition and to reproduce the coupling between acoustics and chemical reactions when the ambient conditions promote a deflagration to detonation transition.

\section{Conclusion}

A model called IPRS was introduced to predict abnormal combustions in IC engines in the context of LES. This model uses a single reduced chemical scheme (with two reactions) to describe both autoignition (AI) and propagation. This is obtained by using a different pre-exponential constant of the fuel decomposition Arrhenius law at low and high temperatures. The low temperature value of the constant used for AI does not impact the flame propagation since the main part of the heat release occurs at high temperatures: the constant can be tuned at low temperatures to correctly capture the AI process and be changed at high temperatures to predict propagation. The IPRS model has been successfully applied to several laminar configurations (autoiginition and 
premixed flames) and to configurations close to IC engines. Its application to one-dimensional single hot spot cases also permits to highlight the different modes of reaction after autoignition and the conclusions of $[24,25]$ were retrieved.

\section{Acknowledgments}

The authors gratefully acknowledge IFPEn for fruitful discussions. This work was granted access to the HPC resources of CCRT under allocations 2012-026074 made by GENCI (Grand Equipement National de Calcul Intensif). The authors acknowledge the financial support by the French ANR under grant ANR-10-VPTT-0002 ICAMDAC.

\section{References}

[1] V. Granet, O. Vermorel, C. Lacour, B. Enaux, V. Dugué, T. Poinsot, Combust. Flame 159 (4) (2012) 1562-1575.

[2] B. Enaux, V. Granet, O. Vermorel, et al., Proc. Combust. Inst. 33 (2011) 3115-3122.

[3] O. Vermorel, S. Richard, O. Colin, C. Angelberger, A. Benkenida, D. Veynante, Combust. Flame 156 (8) (2009) 1525-1541.

[4] D.F. Davidson, M.A. Oehlschlaeger, J.T. Herbon, R.K. Hanson, Proc. Combust. Inst. 29 (2002) 1295-1301.

[5] X. He, M.T. Donovan, B.T. Zigler, et al., Combust. Flame 142 (3) (2005) 266-275.

[6] D.C. Horning, D.F. Davidson, R.K. Hanson, J. Prop. Power 18 (2) (2002) 363-371.
[7] C.K. Westbrook, W.J. Pitz, O. Herbinet, H.J. Curran, E.J. Silke, Combust. Flame 156 (1) (2009) 181-199.

[8] O. Colin, A. Piresda Cruz, S. Jay, Proc. Combust. Inst. 30 (2) (2005) 2649-2656.

[9] N. Peters, B. Kerschgens, G. Paczko, SAE Paper (2013-01-1109), 2012.

[10] M.P. Halstead, L.J. Kirsch, C.P. Quinn, Combust. Flame (1977) 45-60.

[11] E.M. Sazhina, S.S. Sazhin, M.R. Heikal, C.J. Marooney, Fuel 78 (4) (1999) 389-401.

[12] C. Pera, V. Knop, Fuel 96 (0) (2012) 59-69.

[13] P. Schmitt, T. Poinsot, B. Schuermans, K.P. Geigle, J. Fluid Mech. 570 (2007) 17-46.

[14] B. Franzelli, E. Riber, M. Sanjosé, T. Poinsot, Combust. Flame 157 (7) (2010) 1364-1373.

[15] C. Hasse, M. Bollig, N. Peters, H.A. Dwyer, Combust. Flame 122 (1-2) (2000) 117-129.

[16] P. Quillatre, O. Vermorel, T. Poinsot, P. Ricoux, Ind. Eng. Chem. Res. 52 (33) (2013) 11414-11423.

[17] A. Sánchez, A. Lépinette, M. Bollig, A. Linán, B. Lázaro, Combust. Flame 123 (2000) 436-464.

[18] E. Fernandez-Tarrazo, A. Sanchez, A. Linan, F.A. Williams, Combust. Flame 147 (1-2) (2006) 32-38.

[19] B. Franzelli, E. Riber, L.Y. Gicquel, T. Poinsot, Combust. Flame 159 (2) (2012) 621-637.

[20] D.G. Goodwin, Cantera, 2009.

[21] S. Jerzembeck, N. Peters, P. Pepiot-Desjardins, H. Pitsch, Combust. Flame 156 (2) (2009) 292-301.

[22] J.M. Anderlohr, R. Bounaceur, A. Pires DaCruz, F. Battin-Leclerc, Combust. Flame 156 (2) (2009) 505-521.

[23] T. Poinsot, D. Veynante, Theoret. Numer. Combust. (2011).

[24] D. Bradley, G.T. Kalghatgi, Combust. Flame 156 (12) (2009) 2307-2318.

[25] X.J. Gu, D.R. Emerson, D. Bradley, Combst. Flame 133 (1-2) (2003) 63-74. 